\title{
MOLECULAR ANALYSIS OF A PATIENT WITH BECKWITH-WIEDEMANN SYNDROME, RHABDOMYOSARCOMA AND RENAL CELL CARCINOMA
}

\author{
Tadashi Matsumoto, ${ }^{1}$ Ei-ichi Kinoshita, ${ }^{1}$ Hidenori Maeda, ${ }^{1}$ \\ Norio NiIKawa, ${ }^{2}$ Nobuko Kurosaki, ${ }^{3}$ Naoki Harada, ${ }^{4}$ \\ Kankatsu Yun, ${ }^{5}$ Tomoko SAwaI, ${ }^{1}$ Shigeru AokI, ${ }^{1}$ \\ Tatsuro KonDOH, ${ }^{1}$ and Yoshiro TsuJI ${ }^{1}$ \\ ${ }^{1}$ Department of Pediatrics, ${ }^{2}$ Human Genetics, and ${ }^{3}$ Pediatric Surgery, \\ Nagasaki University School of Medicine, Sakamoto, Nagasaki 852, Japan \\ ${ }^{4}$ Kyusyu Medical Science, Hamaguchi-machi, Nagasaki 852, Japan \\ ${ }^{5}$ Department of Pathology, University of Otago Medical School, \\ PO Box 913, Dunedin, New Zealand
}

\begin{abstract}
Summary We described a patient with Beckwith-Wiedemann syndrome associated with rhabdomyosarcoma (RMS), and renal cell carcinoma (RCC). Karyotypes of peripheral lymphocytes and RMS cells were normal. DNA analyses showed maternal loss of heterozygosity (LOH) at $11 \mathrm{p} 15$ region in RMS but not in RCC. The insulin-like growth factor II gene (IGF2) was found to be expressed at a moderate level in RMS but not in RCC by in situ hybridization. Each of parental allele-derived IGF2 transcript was detected in RCC, while maternal allele-derived transcript was weak in RMS because of maternal LOH. These results suggest that (1) loss of imprinting (LOI) of IGF2 might be responsible for BWS, (2) on the other hand, LOI itself might not induce tumor occurrence in tissues where the control of tissue-specific expression of $I G F 2$ is maintained, (3) increased expression of $I G F 2$ due to maternal loss of a putative controller gene for $I G F 2$ at $11 \mathrm{p} 15$ might predispose to sustaining tumorigenic mutations and tumor progression, (4) loss of a putative onco-suppressor gene at $11 \mathrm{p} 15$ might induce RMS occurrence. The cause of RCC was thought to be different from that of RMS.

Key Words Beckwith-Wiedemann syndrome, rhabdomyosarcoma, renal cell carcinoma, insulin-like growth factor II gene, loss of heterozygosity, loss of imprinting
\end{abstract}

Received November 11, 1993, Revised version accepted February 14, 1994. 


\section{INTRODUCTION}

Beckwith-Wiedemann syndrome (BWS) is a congenital overgrowth syndrome, which is sometimes associated with embryonal tumors, such as Wilms tumor, rhabdomyosarcoma (RMS), hepatoblastoma and adrenal carcinoma (Cohen, 1989). The BWS locus is localized to $11 \mathrm{p} 15$, where the genes for insulin (INS) and insulinlike growth factor II (IGF2) are also mapped; the latter might be responsible for perinatal gigantism and visceromegaly in BWS. In sporadic cases of BWS, paternal uniparental disomy or partial trisomy of paternal origin involving an $11 \mathrm{pl}$ region have been known (Henry et al., 1991; Mannens, 1991), while the predominance of maternal transmission of the disease in familial BWS cases have been reported (Niikawa et al., 1986). Moreover, there is evidence that IGF2 is maternally imprinted (paternally expressed) in both the mouse and the human (Rainier et al., 1993). Therefore, a role of $I G F 2$ in a cause of BWS and/or tumor occurrence or progression is highlighted.

Here, we describe a BWS patient who developed in a short period rhabdomyosarcoma and renal cell carcinoma, together with the results of cytogenetic and molecular analyses which confirmed loss of heterozygosity (LOH) for a part of $11 \mathrm{p} 15$ in the RMS cells.

\section{MATERIALS AND METHODS}

Patient. The patient is a 3-year-old boy. He was born at the 37 th week of gestation to non-consanguineous parents with a birth weight of $3,430 \mathrm{~g}(+1.3 \mathrm{SD})$. He suffered from tachypnea and feeding difficulty on day 1 and admitted to our hospital. He had a macroglossia, diastasis recti, hepatomegaly and hypoglycemia $(20-30 \mathrm{mg} / \mathrm{dl})$. Ear lobes were of normal appearance. He was diagnosed as BWS. At age 22 months, a lower abdominal mass was found and a needle biopsy revealed an embryonal type of rhabdomyosarcoma. The patient was treated according to the Intergroup Rhabdomyosarcoma Study (IRS) III protocol, then the tumor mass was subtotally resected, and irradiation was done to the peritoneal region during the surgical operation. At age 37 months during the following chemotherapy, another tumor was detected in the right kidney by computed tomography. The second tumor was totally removed and the same chemotherapy regimen has been going on. Pathological examination revealed that the second tumor was not a Wilms tumor but a renal cell carcinoma (RCC).

Chromosome analysis. Chromosome analyses with conventional and high resolution GTG-banding were done on cultured peripheral blood lymphocytes. As for RMS, a resected fresh tissue was minced with scissors and treated with a solution containing $0.8 \%$ collagenase and $0.002 \% \mathrm{DNase} I$ for $15 \mathrm{~min}$. The cell pellet was washed with PBS and cultured for 10 days with the ES medium (Nissui) 
supplemented with $20 \%$ FBS. G-banding chromosome analysis was performed in 20 metaphase cells. RCC tissue was not available for karyotype analysis.

Molecular analysis. DNA from peripheral blood leukocytes (PB) of patient and his parents and from the RMS tissue was digested with several endonucleases and analyzed with Southern hybridization. Probes used were genomic DNA for the tyrosine hydroxylase gene $(T H), I N S$, and $I G F 2$ (kindly given by Dr. G. I. Bell), $c$-H-ras (from JCRB) and D11S12 (kindly given by Dr. Y. Nakamura). Another part of DNA was used for a polymerase chain reaction (PCR) assay to detect microsatellite nucleotide repeat polymorphism and restriction fragment length polymorphisms (RFLPs) for TH (Human Gene Mapping 11, 1991), IGF2 (Ogawa et al., 1993a), $H 19$ (Rainier et al., 1993; Matsumoto et al., 1994a), the Wilms tumor suppressor gene (WT1) (Zhang and Tycko, 1992; Matsumoto et al., 1994b) and D11S527 (Human Gene Mapping 11, 1991). Each primer was synthesized by Gene Assembler Plus (Pharmacia LKB). PCR was done as described previously (Kinoshita et al., 1991). Single strand conformation polymorphism (SSCP) analysis was also done for WT1, H19, and INS. Reverse transcriptase-based PCR (RT-PCR) was done for IGF2 on RNA extracted from RMS, RCC, and PB. These products were excised and eluted out from gel, then an aliquot was used for endonuclease digestion and nested PCR.

Messenger RNA in situ hybridizatiom. A 534 bp IGF2 cDNA fragment subcloned into pGEM-3 was labeled with digoxigenin-UTP and was used as sense and anti-sense RNA probes. Sample preparation and hybridization were done as described previously (Yun, 1993).

\section{RESULTS}

Chromosome analysis

Both peripheral blood lymphocytes and RMS cells showed a normal 46,XY karyotype.

\section{Southern blot analysis}

Loss of heterozygosity ( $\mathrm{LOH}$ ) was observed at the $T H$ locus in the RMS cells (Fig. 1); maternally-derived 2.8 and $2.0 \mathrm{~kb}$ fragments observed in leukocytes were absent in the RMS tissue. Southern analysis also showed maternal LOH in the IGF2 and INS loci (data not shown), while the other two loci (c-H-ras and DIIS12) were not informative for polymorphisms in this family.

\section{$P C R$ analysis}

Informative data were obtained in an RFLP at the $I G F 2$ locus, a tetranucleotide repeat polymorphism (TNRP) at the $T H$ locus and a dinucleotide repeat polymorphism (DNRP) at the D11S527 locus. The Apal-digest of IGF2/PCR product (primers, P2/P3) showed a homozygous pattern for the $231 \mathrm{bp} / 61 \mathrm{bp}$ allele in the 


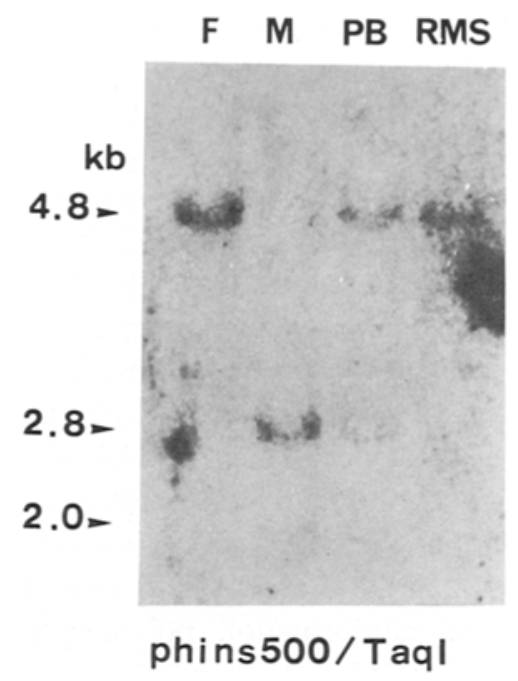

Fig. 1. Southern blot analysis of the pedigree including tumor tissues. DNA (10 $\mu \mathrm{g})$ was digested with TaqI and hybridized with the tyrosine hydroxylase gene genomic probe, phins 500 . Father (F) was homozygous for a $4.8 \mathrm{~kb}$ fragment, mother (M) homozygous for $2.8 \mathrm{~kb} / 2.0 \mathrm{~kb}$ bands, and the patient's leukocytes (PB) heterozygous for both alleles, while the rhabdomyosarcoma cell (RMS) was hemizygous for the $4.8 \mathrm{~kb}$ fragment.

a

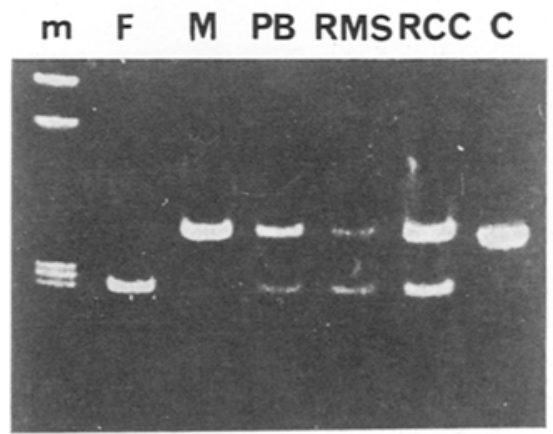

IGF2/Ada| b

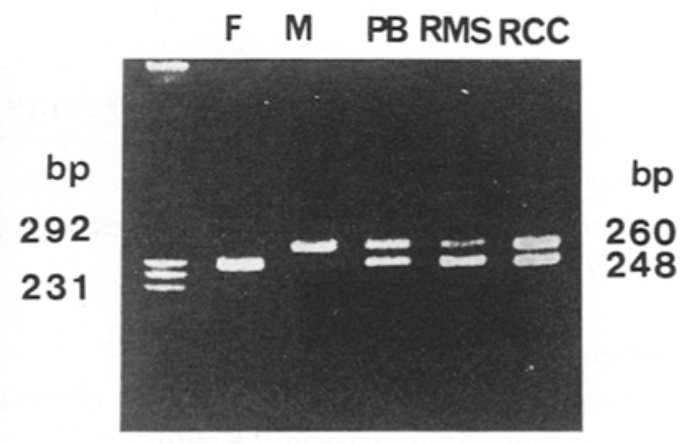

TH

Fig. 2. ApaI digested $I G F 2$ PCR products (a). PCR products were digested with ApaI, separated on $6 \%$ polyacrylamide gel and stained with ethidium bromide (EtBr). Father (F) and mother (M) are homozygous for a 231 bp allele and for a $292 \mathrm{bp}$ allele, respectively. Patient's peripheral leukocytes (PB), rhabdomyosarcoma (RMS), and renal tumor (RCC) are all heterozygous for both alleles, but the band intensity of the maternal allele in RMS is weak compared to that of PB or RCC. C, control, non-digested IGF2 product. Left lane shows a size marker. PCR products of TH (b). PCR products were electrophoresed on $6 \%$ acrylamide gel and stained with EtBr. The band intensity of the maternal allele in RMS is reduced as in (a). 
Table 1. Gene order and heterozygosity in the BWS patient.

\begin{tabular}{lcccccccc}
\hline \multirow{2}{*}{$\begin{array}{c}\text { Tissue } \\
\text { examined }\end{array}$} & HRASI & TH & INS & $I G F 2$ & $H 19$ & D11S12 & WT1 & D11S527 \\
\cline { 2 - 9 } & NI & H & H & H & NI & NI & NI & H \\
\hline PB & & LOH & LOH & LOH & & & & H \\
RMS & & nd & nd & H & & & & H \\
RCC & & & &
\end{tabular}

PB, peripheral blood; Rh, rhabdomyosarcoma; RT, renal tumor; NI, not informative; H, heterozygous; LOH, loss of heterozygosity; nd, not done.

father, a homozygous pattern for a $292 \mathrm{bp}$ allele in the mother, and a heterozygous pattern for the two alleles in PB and RCC of the patient. In the RMS tissues, the intensity for the $292 \mathrm{bp}$ maternally-derived allele was much low, compared with those in PB and RCC (Fig. 2a). Similar findings were obtained in TH-TNRP (Fig. 2b). At the D11S527 locus, the PCR products from each of the two tumor tissues showed an equal intensity between the maternal and paternal alleles (data not shown). Other polymorphisms, WT1/HinfI RFLP, WT1/3' dinucleotide (CA) repeat polymorphism, H19/RsaI, AluI, and HhaI RFLPs, H19-, WTI-, and INSSSCPs, were all uninformative in this family. The results of Southern blot and PCR analyses were summarized in Table 1.

The IGF2 RT-PCR product was digested with PstI or ApaI. Pst I digests of 1,123 bp IGF2/RT-PCR products (primers, P1/P3) from each of RMS and RCC tissues gave 851,351 , and 21 bp fragments which coincided with the restriction map of the IGF2 cDNA. ApaI digestion revealed 892 and 231 bp fragments and a very weak 1,123 bp fragment from RMS. By nested PCR with primers P2/P3, 292 bp fragments were amplified from both of the tumors. ApaI digests gave 292, 231, and $61 \mathrm{bp}$ fragments from RCC, while $292 \mathrm{bp}$ fragment from RMS was very weak in intensity (Fig. 3, a, b, and c). PB of the patient also revealed both of parental allele-derived transcripts (Fig. 3c).

mRNA in situ hybridization

The IGF2 transcript was detected in moderate levels in the cytoplasm of the RMS cells, while the transcript was almost absent in the co-existing fibrous tissue of RMS and RCC and the surrounding normal renal tissue (Fig. 4).

\section{DISCUSSION}

The frequency of complication of embryonal tumors is high in BWS patients, and rhabdomyosarcoma is the one of the associated tumors. It has been known that such an embryonal tumor tissue often shows LOH that involves loss of oncosuppressor gene(s). Southern blot and PCR analyses in the RMS from our BWS 
a

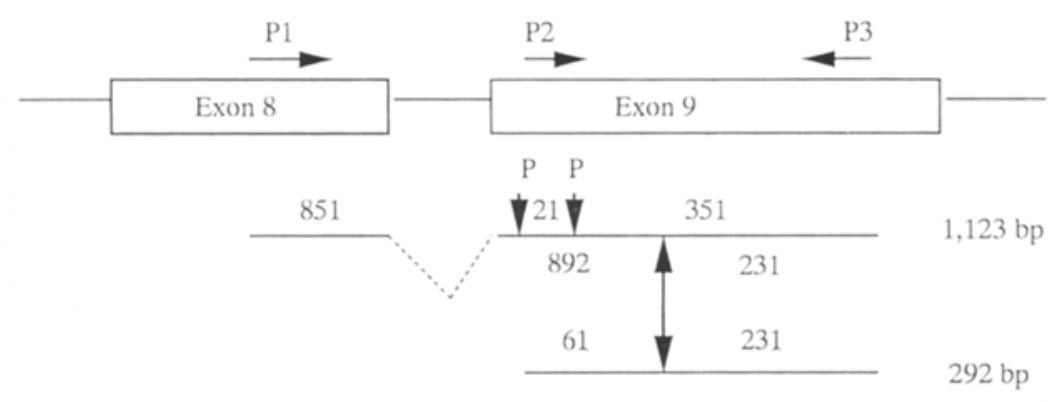

b

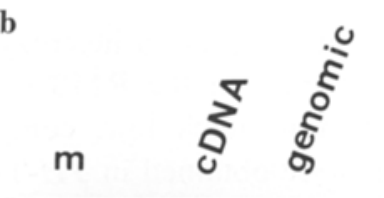

c
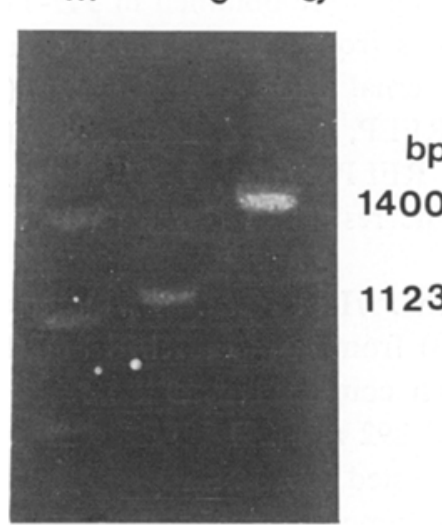

\section{m RMSRCC m C PB}

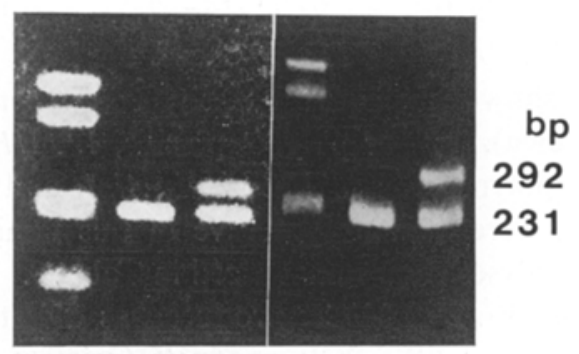

RT-PCR

IGF2/Apa I

Fig. 3. IGF2 RT-PCR products from rhabdomyosarcoma cells. a) IGF2 gene map and sites of primers (PI-3) (a). $P$ indicates $P_{s t} I$ sites. Bi-directional arrow shows a polymorphic ApaI site. RT-PCR and genomic PCR products from RMS tissue using primers P1 and P3 (b). c) P1/P3 RT-PCR products from RMS, RCC, and PB underwent nested PCR using primers P2/P3, then the products were digested by ApaI (c). RCC and PB showed both of parental allelederived transcripts, while maternal allele-derived transcript in RMS was weak in intensity. $C$, peripheral blood from normal control; $m$, size marker.

Fig. 4. mRNA in situ hybridization with IGF2. A high magnification of embryonal rhabdomyosarcoma (original magnification, $\times 450$, hematoxylin-eosine) (A). In situ hybridization of RMS in which virtually all tumor cells contain abundant IGF2 transcripts (original magnification, $\times 450$, no counterstaining) (B). Renal clear cell carcinoma (original magnification, $\times 225$, hematoxylin-eosine) (C). In situ hybridization of RCC in which no IGF2 transcripts were detected (original magnification, $\times 225$, no counterstaining) (D). 

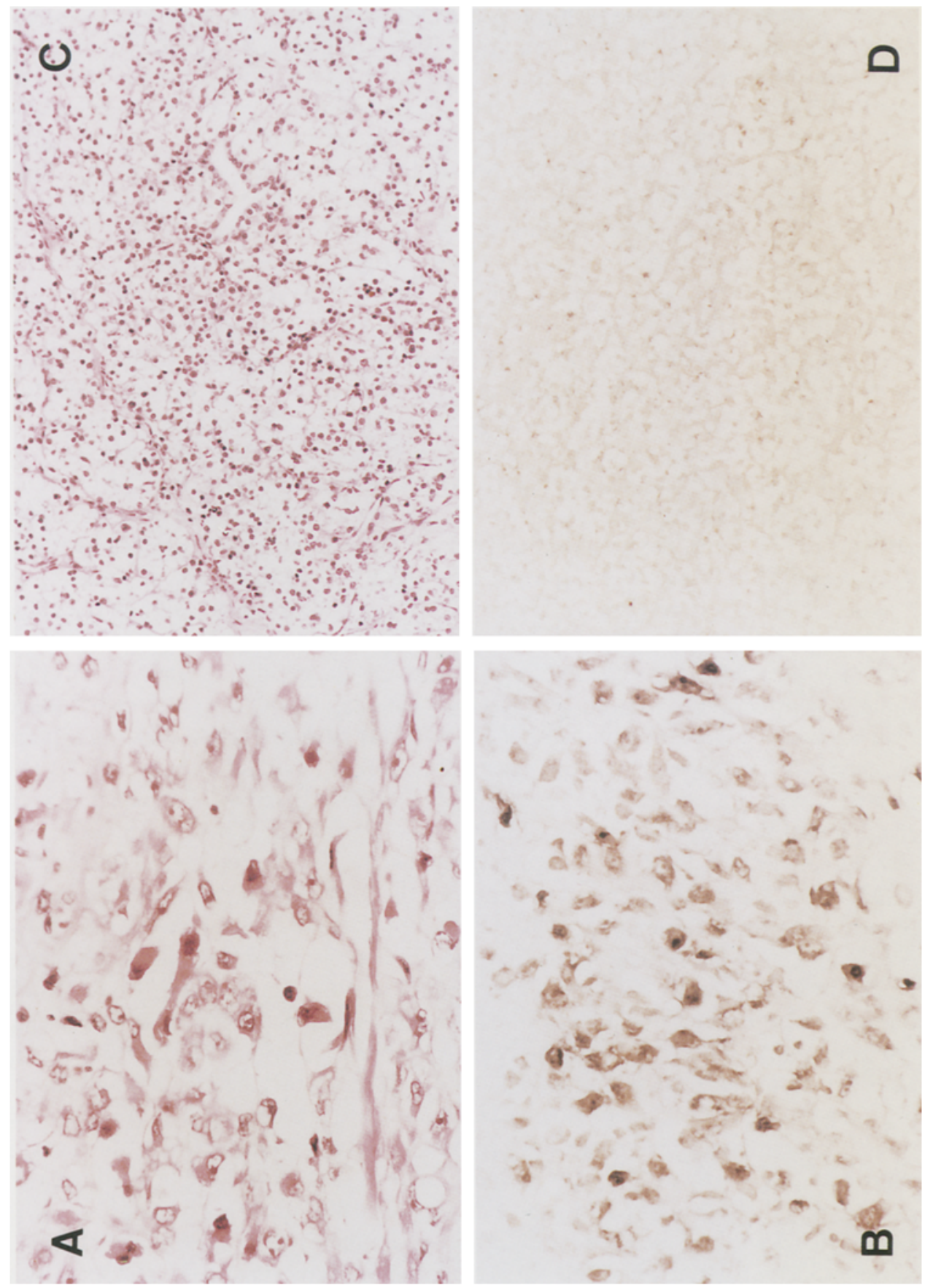

Vol. 39, No. 2, 1994 
patient showed maternal LOH at the $T H, I N S$, and IGF2 loci all located to $11 \mathrm{p} 15.5$. As $D 11 S 12$ at $11 \mathrm{p} 15.5$ and $W T 1$ at $11 \mathrm{p} 13$ were not informative in this family, we could not estimate a deletion extent on the chromosome 11 in the tumor cells. It seems less likely that the extent was large, because in the tumor tissue on visible deletion was seen by chromosome analysis.

$I G F 2$ expression is controlled by tissue- and development-specific ways. IGF2 has four different promoters and the use of each promoter seems to depend on different tissue-specific transcription factors (Sussenbach et al., 1992). IGF2 is known to be maternally imprinted: only the paternally-derived allele is active, while the maternally-derived one is inactive during embryogenesis and also in one BWS patient (Ohisson et al., 1993). Recently, bi-allelic expression of H19 and $I G F 2$, namely, relaxation of imprinting or loss of imprinting (LOI) has been reported in Wilms tumor tissues, and the LOI may be causally related to tumorigenesis ( $O$ gawa et al., 1993a; Rainier et al., 1993). Because of LOH at 11p15 in RMS of our patient, the tumor cell itself might express $I G F 2$ only from paternally-derived allele, while both of parental alleles of IGF2 were transcribed in $\mathrm{RCC}$, leukocytes and probably in normal fibrous tissue of RMS. These results suggest that LOI might occur in the whole body in our patient and result in the occurrence of BWS. Very recently, LOI has been reported in some tissues including Wilms tumor of a patient with gigantism (Ogawa et al., 1993b) and in 4 of 6 BWS fibroblast strains (Weksberg et al., 1993). Therefore, bi-allelic expression of $I G F 2$ due to a mutation of a putative cis- or trans-acting element on maternally transmitted chromosome 11 which induces imprinting of $I G F 2$, or paternal disomy of $11 \mathrm{p} 15$ might induce overexpression of $I G F 2$ resulting in BWS. In this contex, $H 19$ is very interesting, because it is located near the IGF2 locus (Zemel et al., 1992) and known to be imprinted inversely to IGF2 (Zhang and Tycko, 1992). It might be associated with $I G F 2$ imprinting, because it may function as the nuclear RNA (Brannan et al, 1990), as in case of XIST on X chromosome inactivation (Brown et al., 1991). We could not elucidate the imprinting status of the $H 19$ gene in either of the tumor tissues, since any $H 19$ polymorphisms were uninformative in our family.

In situ hybridization revealed that the IFG2 transcript in the tissue level was moderate in RMS cells but almost nil in RCC and the fibrous tissue of RMS, although both parental $I G F 2$ alleles were expressed on RT-PCR analysis. Renal cell carcinoma is derived from the renal epithelium in which $I G F 2$ expression is absent even in the fetal kidney (Yun, 1993). These data suggest that bi-allelic expression of $I G F 2$ itself might not mean increased expression of $I G F 2$, nor induce tumor occurrence and/or progression, especially in tissues where IGF2 is not usually expressed and/or when $I G F 2$ expression is developmentally regressed. The increased expression of $I G F 2$ in some tissues may influence the growth of tumor(s). It is known that $I G F 2$ expression is increased in some tumor tissues including embryonal tumors (Sussenbach et al., 1992). In some tumors involving LOH at $11 \mathrm{p} 15$, loss of the function of a putative onco-suppressor gene at $11 \mathrm{p} 15$ (Koi et al., 1993) might induce the tumor occurrence and progression. Therefore, the constitutional bi- 
allelic expression of $I G F 2$ may cause somatic overgrowth, which predisposes to tumorigenic mutations (Chao et al., 1993) and/or rapid growth of tumor by the IGF2 autocrine mechanism.

Our patient developed two different neoplasms, RMS and RCC, in a short period. These two tumors might have occurred through different mechanisms of tumorigenesis, because the LOH of chromosome $11 \mathrm{p}$ was seen in RMS but not in RCC. The former was likely associated to BWS, whereas a mechanism of the occurrence of the latter remained unknown but could be associated to irradiation and/or chemotherapy as in the case of Banner et al. (1977) or to other gene abnormality such as a putative onco-suppressor gene on chromosome $3 p$ (Knudson, 1993).

\section{REFERENCES}

Banner MP, Bleshman MH, Novicki DE (1977): Renal cell carcinoma in a patient successfully treated for Wilms tumor. Am J Roentgenol 128: 77-80

Brannan CI, Dees EC, Ingram RS, Tilghman SM (1990): The product of the $H 19$ gene may function as an RNA. Molec Cell Biol 10: $28-36$

Brown CJ, Ballabio A, Rupert JL, Lafreniere RG, Grompe M, Tonlorenzi R, Willard HF (1991): A gene from the region of the human $X$ inactivation center is expressed exclusively from the inactive $X$ chromosome. Nature 349: 38-44

Chao LY, Huff V, Tomlinson G, Riccardi VM, Strong LC, Saunders GF (1993): Genetic mosaicism in normal tissues of Wilm's tumour patients. Nature Genet 3: 127-131

Cohen MM Jr (1989): A comprehensive and critical assessment of overgrowth and overgrowth syndromes. In: H Harris and $\mathrm{K}$ Hirschhorn (eds). Advances in human genetics, Vol. 18, pp 181303, Plenum Press, New York

Henry I, Bonaiti-Peellie C, Chehensse V, Beldjord C, Schwartz C, Utermann G, Junien C (1991): Uniparental disomy in a genetic cancer-predisposing syndrome. Nature 351: 665-667

Human Gene Mapping 11. London Conference (1991): Cytogenet Cell Genet 58: 1663-1696

Kinoshita E, Matsumoto T, Kondoh T, Yoshimoto M, Niikawa N, Tsuji Y (1991): Deletion pattern in the 21-hydroxylase gene detected by polymerase chain reaction. Acta Pediatr Jpn 33: $1-5$

Koi M, Johnson LA, Kalikin LM, Little PFR, Nakamura Y, Feinberg AP (1993): Tumor cell growth arrest caused by subchromosomal transferable DNA fragments from chromosome 11 . Science 260: $361-364$

Knudson AG (1993): Introduction of the genetics of primary renal tumors in children. Med Pediatr Oncol 21: 193-198

Mannens M (1991): The molecular genetics of Wilm's tumor and associated congenital diseases. University of Amsterdam, Amsterdam

Matsumoto T, Okumura M, Sawai T, Aoki S, Tsuji Y (1994a): Allele frequency of HinfI restriction fragment length polymorphism (RFLP) and dinucleotide repeats polymorphism in Wilms tumor gene 1 (WT1) among the Japanese. Jpn J Human Genet 39: 207-208

Matsumoto T, Aoki S, Sawai T, Tsuji Y (1994b): A novel H19/HhaI RFLP and its allele frequency in the Japanese. Jpn J Human Genet 39: 205-206

Niikawa N, Ishikiriyama S, Takahashi S, Inagawa A, Tonoki H, Ohta $Y$, Hase N, Kamei T, Kajii $\mathrm{T}$ (1986): The Wiedemann-Beckwith syndrome: pedigree studies on five families with evidence for autosomal dominant inheritance with variable expressivity. Am J Hum Genet 24: 41-55

Ogawa O, Eccles MR, Szeto J, McNoe LA, Yun K, Maw MA, Smith PJ, Reeve AE (1993a): Re- 
laxation of insulin-like growth factor II gene imprinting implicated in Wilms' tumor. Nature 362: 749-751

Ogawa O, Becroft DM, Morison IM, Eccles MR, Skeen JE, Mauger DC, Reeve AE (1993b): Constitutional relaxation of insulin-like growth factor II gene imprinting associated with Wilms' tumour and gigantism. Nature Genet 5: 408-412

Ohlsson R, Nystrom A, Pfeifer-Ohlsson S, Tohonen V, Hedborg F, Schofield P, Flam F, Ekstrom T (1993): IGF2 is parentally imprinted during human embryogenesis and in the BeckwithWiedemann syndrome. Nature Genet 4: 94-97

Rainier S, Johnson LA, Dobry CJ, Ping AJ, Grundy PE, Feinberg AP (1993): Relaxation of imprinted genes in human cancer. Nature 362: 747-749

Sussenbach JS, Steenberg PH, Holthuizen P (1992): Structure and expression of the human insulinlike growth factor genes. Growth Regulation 2: 1-9

Van Heyningen V, Hastie ND (1992): Wilm's tumor: reconciling genetics and biology. Trends Genet 8: 16-21

Weksberg R, Shen DR, Fei YL, Song QL, Squire J (1993): Disruption of insulin-like growth factor 2 imprinting in Beckwith-Wiedemann syndrome. Nature Genet 5: 143-150

Yun K (1993): Clear cell sarcoma of the kidney expresses insulin like growth factor-II but not WT1 transcripts. Am J Pathol 142: 39-47

Zemel S, Bartolomei MS, Tilghman SM (1992): Physical linkage of two mammalian imprinted genes, $\mathrm{H} 19$ and insulin-like growth factor 2. Nature Genet 2: 61-64

Zhang Y, Tycko B (1992): Monoallelic expression of the human H19 gene. Nature Genet 1: 40-44 